\title{
VISI KEPEMIMPINAN DIGITAL KEPALA SEKOLAH DASAR DI ERA TEKNOLOGI DIGITAL
}

\author{
Moh. Muslim \\ Universitas Islam Malang \\ e-mail: moh.muslim@unisma.ac.id
}

Diterima: 16 September 2020 I Direvisi: 02 November 2020 I Disetujui: 30 Maret 2021 (C) 2021 Pendidikan Guru Madrasah Ibtidaiyah Fakultas Agama Islam Universitas Islam Malang

\begin{abstract}
Abstrak
Tujuan dari penelitian ini adalah untuk mengetahui kepemimpinan digital kepala sekolah dasar di era teknologi digital. Penelitian ini menggunakan pendekatan kualitatif dengan jenis penelitian studi kasus. Pengumpulan data dilakukan dengan wawancara mendalam, observasi partisipan dan dokumentasi. Analisis data dilakukan dengan menggunakan analisis interaktif dengan tahapan pengumpulan data, kondensasi data, penyajian data dan penarikan kesimpulan. Untuk menjaga keabsahan data digunakan teknik triangulasi. Beberapa hasil penelitian menyimpulkan bahwa kepala sekolah mengembangkan visi yang mencerminkan orientasi pengembangan visi sekolah berbasis perkembangan teknologi digital. Temuan penelitian 1) manajemen sekolah berbasis teknologi, 2) perencanaan strategis berbasis teknologi, 3) forum diskusi kelompok berbasis teknologi, 4) evaluasi berkala berbasis teknologi dan 5) pengembangan program berbasis pengalaman lapangan.
\end{abstract}

Kata kunci: visi kepemimpinan digital, kepala sekolah, teknologi digital.

\begin{abstract}
The purpose of this study is to investigate the digital leadership of primary school principals in the era of digital technology. This research uses a qualitative approach using a case study research type. Data were collected by means of in-depth interviews, participant observation and documentation. Data analysis was performed using interactive analysis with the stages of data collection, data condensation, data presentation and conclusion drawing. To maintain data validity, triangulation techniques were used. Several research results concluded that the principal developed a vision which reflected an orientation towards developing a school vision based on the development of digital technology. Research findings 1) technology-based school management, 2) technology-based strategic planning, 3) technology-based group discussion forums, 4) technology-based periodic evaluation and 5) field experience-based program development.
\end{abstract}

Key words: digital leadership vision, school principal, digital technology.

\section{PENDAHULUAN}

Pola hidup masyarakat mengalami perubahan yang sangat cepat, seiring dengan perubahan era teknologi industry 4.0. (Alexandru et al., 2019). Transformasi digital berpangkal pada perubahan yang terkait dengan penerapan 
teknologi digital di semua aspek kehidupan manusia. Revolusi digital ini menyebabkan peningkatan fleksibilitas dalam produksi, peningkatan kecepatan, dimensi baru produksi massal, tingkat produktivitas yang maju, hasil kualitas yang unggul, dan model bisnis baru yang muncul (Oberer and Erkollar, 2018). Revolusi digital telah mendatangkan kemajuan luar biasa dalam pengumpulan informasi, kecepatan dan volume transmisi informasi, mode penerimaan, dan luasnya akses.

Teknologi digital telah mengubah hampir setiap aspek kehidupan kita selama beberapa dekade terakhir termasuk cara kita berkomunikasi, berbelanja, dan membaca. Teknologi digital, memiliki potensi menawarkan solusi yang diperlukan bagi kehidupan manusia jika didukung oleh investasi yang memadai dan dukungan peraturan (Medicine, 2019).

Dampak dari perkembangan tersebut memunculkan tantangan dan persoalan yang semakin komplek (Moos, 2003). Kepala sekolah sebagai penanggung jawab atas keberlangsungan penyelenggaraan pendidikan.

Kemampuan untuk selalu melakukan upaya pengembangan di dalam menghadapi berbagai tantangan yang sedang berkembang adalah merupakan kunci keberlangsungan lembaga pendidikan di era global (Ruiz et al., 2019). Kepala sekolah memiliki peran penting dalam menyiapkan respon lembaga mereka terhadap segala perubahan, dan dalam praktiknya kepala sekolah dituntut untuk tetap mampu membangun kepercayaan, kolaborasi, dan kepemimpinan kolaboratif dalam segala situasi. Sukses atau tidaknya sekolah, secara fundamental sangat dipengaruhi oleh kepemimpinan kepala sekolah (Kurland, Peretz and Hertz-Lazarowitz, 2010).

Kepala sekolah dasar harus memiliki visi kepemimpinan. Visi kepemimpinan sangat penting untuk menghadapi adanya perubahan kondisi krusial (Heikka et al., 2019). Visi kepemimpinan menjadi kunci keberhasilan bagi kepala sekolah, agar mampu untuk tetap eksis dalam berbagai perubahan situasi dan kondisi (Fullan et al., no date). Hasil dari beberapa penelitian yang telah ada diperoleh temuan bahwa kepemimpinan digital dapat meningkatkan dan dapat mendorong proses pengajaran dan pembelajaran digital (Richardson et al., 2012). Kepemimpinan merupakan aksi nyata (Sheninger, 2014) untuk mempengaruhi (Oberer and Erkollar, 2018) mengelola sumberdaya manusia dan non manusia (Anwaruddin, 2009) dalam rangka menjaga perkembangan (Moos, 2003) masa depan lembaga. Pada waktu yang bersamaan yang sama, untuk mengelola kegiatan dengan instruksi yang jelas (Fried, 2017) distribusi kerja (Mifsud, 2017), (Oberer and Erkollar, 2018). 
Kepemimpinan digital merupakan seni mengarahkan, mempengaruhi orang lain, dan memulai perubahan yang berkelanjutan melalui akses informasi, dan membangun hubungan untuk mengantisipasi perubahan penting bagi keberhasilan sekolah di masa depan. Untuk itu, dibutuhkan kombinasi yang dinamis dari pola pikir, perilaku, dan keterampilan yang digunakan untuk mengubah atau meningkatkan budaya sekolah melalui bantuan teknologi (Sheninger, 2014). Kerangka kerja kepemimpinan digital ini dirancang berdasarkan kombinasi teknolgi, motivasi dan gaya kepemimpinan (Hamilton, Tee and Prince, 2016);(Frey and Berger, 2016).

Kepemimpinan digital merupakan strategi yang dapat diterapkan oleh pemimpin sekolah dasar untuk meningkatkan prestasi siswa dan meningkatkan daya saing sekolah (Sheninger, 2019). Kepemimpinan digital menjadi salah satu pendekatan yang sangat tepat, cepat, lintas hierarkis, berorientasi kelompok kerja, dan kerjasama, dengan fokus utama pada inovasi (Oberer and Erkollar, 2018). Dibutuhkan komunikasi yang intens dan dua arah antar stakeholder dalam lembaga pendidikan (Sheninger 2014). Pemimpin teknologi dalam dunia pendidikan akan memfasilitasi pengembangan visi bersama, untuk integrasi teknologi yang komprehensif dan menumbuhkan lingkungan dan budaya yang kondusif bagi terwujudnya visi. Visi kepemimpinan dapat diketahui melalui beberapa poin berikut: 1) Mengidentifikasi dan menerapkan penelitian terkait pendidikan dan teknologi, psikologi pembelajaran, dan prinsip-prinsip desain instruksional dalam memandu penggunaan komputer dan teknologi dalam pendidikan, 2) Menerapkan strategi dan pengetahuan tentang masalah yang terkait dengan pengelolaan proses perubahan di sekolah, 3) Menerapkan keterampilan berkelompok secara efektif, 4) Menerapkan Kepemimpinan yang efektif dalam pengembangan dan evaluasi perencanaan teknologi distrik dan keterampilan proses kelompok implementatif, dan 5) Terlibat dalam pengalaman berbasis lapangan yang diawasi dengan fasilitator atau direktur teknologi yang ulung (International Society for Technology in Education, 2009);(ISTE, 2001). Meskipun banyak yang telah ditulis tentang kepemimpinan, akan tetapi konsep visi kepemimpinan digital belum dipahami secara luas, mendalam dan komprehensif (Ndalamba, Caldwell and Anderson, 2018). Untuk itu, dibutuhkan penelitian lanjutan tentang visi kepala sekolah digital, terutama bagi kepala sekolah dasar. Didasarkan pada pendahuluan tersebut, maka penelitian ini berupaya untuk melakukan investigasi terhadap visi kepemimpinan digital kepala sekolah dasar di MIN 1 Kota Malang. 


\section{METODE}

Studi kasus ini difokuskan pada aspek visi kepemimpinan digital kepala sekolah dasar di MIN 1 Kota Malang untuk menghadapi perkembangan era teknologi digital. Tujuan penelitian ini adalah untuk menginvestigasi secara komprehensif, detail dan mendalam terhadap peristiwa dan perilaku kepemimimpinan digital kepala sekolah dasar MIN 1 Kota Malang dengan menggunakan pendekatan kualitatif (qualitative approach) (Jamshed, 2014). Untuk mencapai tujuan penelitian, maka penelitian ini menggunakan rancangan penelitian studi kasus. Proses investigasi dengan mencari jawaban atas pertanyaan 'bagaimana' dan 'mengapa' mengenai masalah yang terkait dengan proses (Yin, 2007). Studi kasus dipilih agar dapat mengelaborasi secara detail, mendalam dan komprehensif terhadap fenomena yang ada di lokasi penelitian (Yin, 2007);(Johnson and Stake, 1996);(Meyer, 2001);(Forrest-Lawrence, 2019);(Meyer, 2001);(Flyvbjerg, 2006).

MIN 1 Kota Malang dipilih karena, MIN 1 Kota Malang menjadi sekolah dasar unggulan di level nasional, memiliki banyak prestasi dan menerapkan pengelolaan lembaga dengan berbasiskan pada pengembangan teknologi (Malang, no date). Untuk memperoleh data yang dibutuhkan sesuai dengan fokus yang diteliti, teknik pengumpulan data menggunakan wawancara mendalam dan observasi partisipan (Crowe et al., 2011);(Jamshed, 2014);(Baxter, Susan Jack and Jack, 2008). Wawancara mendalam dan observasi partisipan digunakan untuk mengeksplorasi berbagai informasi dari responden dan berbagai situasi yang melingkupi pada obyek penelitian. Penetapan responden penelitian dilakukan dengan teknik purposif sampling terhadap tempat dan orang yang paling mengetahui dan menguasai informasi sesuai dengan tujuan peneliti. Standar utama penetapan responden adalah keluasan dan kedalaman informasi yang dimiliki (Creswell, 2012). Selain menggunakan wawancara mendalam dan observasi partisipan, peneliti juga mengumpulkan data penelitian menggunakan teknik analisis dokumen (Creswell, 2012);(Bogdan and Biklen, 2003).

Data hasil penelitian dikelompokkan menjadi data primer dan data skunder (Hox and Boeije, 2004). Data primer mencakup kata-kata dan tindakan yang didapatkan dari informan di lokasi berdasarkan pada fokus penelitian (Meyer, 2001). Data skunder berisikan dokumen-dokumen pendukung yang dapat memperkokoh data primer, agar diperoleh data yang valid dan reliabel (Hox and Boeije, 2004). Informan kunci adalah kepala sekolah dan untuk memperoleh informasi yang lengkap, luas dan mendalam dilakukan teknik snowball sampling (Naderifar, Goli and Ghaljaie, 2017). Validitas data penelitian diperoleh dengan 
tehnik trianggulasi sumber dan metode (Lincoln, Guba and Pilotta, 1985);(Meyer, 2001).

Analisis data kasus visi kepemimpinan digital kepala sekolah dasar MIN 1 Kota Malang menggunakan teknik interaktif. Teknik ini meliputi: kondensasi data (menyeleksi, memfokuskan, menyederhanakan, mengabstraksi dan mentransformasi), penyajian data (menemukan pola dan hubungan antar data yang memungkinkan pengambilan kesimpulan) dan penarikan kesimpulan atau verifikasi (membuat pola tentang peristiwa yang terjadi) (Matthew B, Miles and Saldaña, 2014).

\section{HASIL DAN PEMBAHASAN}

Visi kepemimpinan digital kepala sekolah dasar MIN 1 kota malang di dalam menghadapi perkembangan teknologi industri 4.0 dapat di paparkan berikut ini:

1. Mengidentifikasi dan menerapkan penelitian terkait pendidikan dan teknologi, psikologi pembelajaran, dan prinsip-prinsip desain instruksional dalam memandu penggunaan komputer dan teknologi dalam pendidikan.

Kepala sekolah dasar MIN 1 Kota Malang melakukan identifikasi terhadap kebutuhan dan tantangan yang dihadapi melalui langkah-langkah elaborative terhadap isu-isu aktual yang sedang berkembang di dunia pendidikan maupun masyarakat. Tindakan kepala sekolah ini dapat dilihat dalam berbagai forum dan kesempatan, kepala sekolah mengajak sharing dengan civitas sekolah (wakil kepala, guru, karyawan, orang tua siswa dan siswa). Dari hasil sharing dengan berbagai unsur dalam sekolah inilah, kemudian kepala sekolah membuat dan menyusun poin-poin penting yang nantinya akan dikaji lebih lanjut secara detail dan mendalam. Proses sharing yang dilakukan oleh kepala sekolah tidak hanya terjadi dalam forum-forum formal (resmi), akan tetapi juga berlangsung secara non formal atau informal. Tidak hanya itu, proses diskusipun bisa berlangsung dengan santai dalam forum group whatsapp.

Dari hasil diskusi secara formal, non formal dan secara offline atau online inilah, kemudian ditindak lanjuti dalam forum khusus, yang bertugas untuk mengkaji dan mendalami berbagai persoalan yang relevan dengan tujuan pengembangan yang akan dilakukan oleh sekolah. Dengan demikian kepala sekolah dasar MIN 1 Kota Malang memiliki visi yang jelas bagi upaya untuk pengembangan sekolah dengan mendasarkan pada pengembangan teknologi, dan berbasiskan pada pemanfaatan teknologi. 
Kepala sekolah tidak hanya sekedar memanfaatkan keberadaan teknologi sebagai sarana komunikasi dan interaksi semata, akan tetapi kepala sekolah berupaya mengembangkan manajemen kelembagaan sekolah dengan pengembangan berbasiskan pada teknologi.

Hal tersebut, mengindikasikan bahwa kepala sekolah dasar MIN 1 Kota Malang memiliki visi kepemimpinannya dengan berupaya untuk mengintegrasikan pengelolaan dan layanan sekolah dengan berbasiskan pada teknologi (school management base tecnology). Manajemen sekolah berbasis teknologi selaras dengan teori kepemimpinan digital yang dikembangkan oleh Brett yaitu mengintegrasikan tren teknologi yang berkembang di masyarakat (Brett, 2019).

\section{Menerapkan strategi dan pengetahuan tentang masalah yang terkait dengan pengelolaan proses perubahan di sekolah.}

Tahap ini merupakan tahapan setelah kepala sekolah melakukan elaborasi terkait dengan berbagai persoalan yang dihadapi oleh sekolah, sekaligus tantangan sekolah dalam menghadapi perkembangan yang terjadi di tengah masyarakat. Tahap ini merupakan bentuk kongkrit bagaimana kepala sekolah menyusun formulasi strategis yang akan diambil untuk menjadi sebuah kebijakan. Formulasi strategis kepala sekolah di MIN 1 Kota Malang dapat dilihat dari tersusunnya renstra sekolah (RENSTRA) MIN 1 Kota Malang, yang kemudian secara implementasinya tersusun dalam sebuah Rencana Madrasah (RKM) dan Rencana Kegiatan dan Anggarana Madrasah (RKAM).

Tersusunnya dokumen-dokumen tersebut, menjadi indikator bagi kepala sekolah atas komitmennya untuk selalu konsisten menjalankan visi kepemimpinan yang dimilikinya. Sedangkan keterkaitannya dengan visi kepemimpinan digital kepala sekola, maka dapat dilihat dari komitmen kepala sekolah untuk menyusun rencana kegiatan dan anggaran yang memfokuskan pada pengembangan sumberdaya sekolah, yang berbasiskan pada pengembangan teknologi.

Bila dilihat dari segi komitmen kepala sekolah dasar MIN 1 Kota Malang untuk mengembangkan sumberdaya dengan berbasisikan pada pengembangan teknologi, maka dari Rencana startegsi, rencana kerja dan rencana anggaran yang ditetapkan akan sangat tampak.

Seperti yang dikatakan oleh Brett (Brett, 2019) bahwa salah satu komponen kepemimpinan digital adalah ketrampilan untuk mengorganisasi digital (digital organizing). Pengorganisasian digital di dalamnya mencakup sumber daya manusia dan non manusia.

Dalam perencanannya, kepala sekolah dasar MIN 1 Kota Malang, telah menyusun langkah strategis untuk melakukan pengembangan sumberdaya 
manusia dan non manusia dengan berbasiskan pada teknologi digital (strartegis planing base technology). Perencanaan strategis berbasis teknologi yang disusun oleh kepala sekolah akan menjadi acuan dan pedoman bagi seluruh civitas sekolah di dalam penyelenggaraan pendidikan.

\section{Menerapkan keterampilan berkelompok secara efetif}

Implementasi manajemen sekolah berbasis teknologi yang dikembangkan oleh kepala sekolah dasar MIN 1 Kota Malang termanifestasikan dalam aktivitas kelembagaan secara umum. Sebagaimana praktik keseharian di lingkungan MIN 1 Kota Malang, yang senantiasa mengembangkan forum-forum kelompok untuk menyelesaikan berbagai persoalan yang ada. Kelompok-kelompok yang dikembangkan tidak hanya berkaitan dengan upaya penyelesaian masalah sekolah, akan tetapi juga digunakan untuk pengembangan diri bagi seluruh sumber daya manusia yang ada. Seperti kelompok baca Al-Qur'an, kelompok hafalan, kelompok manajemen, kelompok humas, kelompok wali kelas dan orang tua peserta didik yang semua itu dikelola melalui pemanfaatan teknologi yaitu media komunikasi whatsapp.

Dengan adanya forum-forum kelompok yang berbasiskan pada teknologi tersebut, sangat mempermudah dan membuat proses pengelolaan pendidikan menjadi semakin efektif dan efisien. Berbagai persolan bisa dikoordinasikan dan dikomunikasikan secara cepat dan dapat diambil kebijakan dengan cepat pula. Maka upaya pembentukan kelompok dengan pengembangan berbasiskan teknologi menjadi bentuk riil langkah kepemimpinan digital dalam mengintegrasikan kepemimpinannya berdasarkan pada tren teknologi yang sedang berkembang. Kelompok-kelompok tersebut dapat dikatakan sebagai sarana diskusi bagi sumberdaya yang ada (forum group discutin) berbasiskan teknologi.

\section{Memimpin dalam pengembangan dan evaluasi perencanaan dan implementasi teknologi}

Kepala sekolah melakukan evaluasi secara berkala terhadap keterlaksanaan dari perencanaan yang telah ditetapkan. Secara teknis pelaksanannya dilakukan dalam jangka waktu mingguan, bulanan, semester dan tahunan. Untuk evaluasi mingguan dilakukan oleh tim manajemen, khususnya untuk mengevaluasi progress pendidikan yang bersifat jangka pendek, setelah itu dilanjutkan dengan evakuasi bulanan yang dilakukan secara keseluruhan antara kepala sekolah, wakil kepala sekolah dan guru untuk mengevaluasi secara keseluruhan dari keterlaksanaan program kegiatan dalam satu bulan. Evaluasi semesteran dilakukan untuk mengetahui keterlaksanaan program kegiatan yang dilaksanakan 
dalam jangka waktu satu semester dan evaluasi yang terakhir adalah evaluasi tahunan. Evaluasi tahunan di sekolah disebut dengan Evaluasi Diri Sekolah/Madrasah (EDS/M) untuk mengevaluasi secara keseluruhan program kegiatan berdasarkan pada 8 standart pendidikan.

\section{Terlibat dalam pengalaman yang berbasis lapangan dengan diawasi oleh fasilitator atau direktur teknologi yang ulung}

Kepala sekolah yang mampu memiliki visi kepemimpinan digital dikembangkan dengan cara, kepala sekolah tersebut terlibat secara langsung pada praktik kegiatan yang menggunakan pemanfaatan teknologi dengan dipandu dan didampingi oleh orang yang memiliki kompetensi dalam bidang teknologi tersebut. Kepala sekolah dasar MIN 1 Kota Malang melakukan hal tersebut dalam bentuk workshop dan pelatihan penguatan teknologi informasi untuk seluruh guru dan karyawan. Contoh dari praktik ini adalah penerapan Aplikasi Raport Digital (ARD). ARD adalah aplikasi raport yang wajib untuk seluruh lembaga pendidikan yang berada dibawah payung hukum kementrian agama. Sehingga seluruh sekolah yang berada dibawah kementrian agama menggunakan aplikasi tersebut. Di MIN 1 Kota Malang, kepala sekolah tidak hanya serta merta mengadopsi aplikasi tersebut untuk digunakan di MIN 1 Kota Malang, akan tetapi kepala sekolah memiliki inisiasi untuk melakukan inovasi dan pengembangan dari aplikasi yang telah ada. ARD dari kemenag bukan diadopsi langsung, akan tetapi diadaptasi dan dilakukan upaya pengembangan agar sesuai dengan kebutuhan sekolah. Dengan adanya adaptasi dan inovasi aplikasi inilah, kepala sekolah memiliki pengalaman secara langsung untuk bisa menggunakan sekaligus mengembangkan aplikasi ARD yang ada.

Kemampuan kepala sekolah untuk menginovasi dan mengadaptasi tren teknologi yang sedang berkembang merupakan salah satu bentuk ketrampilan field experience base technology. Berangkat dari field experience base technology inilah, kemudian kepala sekolah menformulasikan visi dan mengembangkan pengelolaan pendidikan di sekolah.

Dari pembahasan di atas, maka dapat diformulasikan dalam bentuk skema berikut ini: 


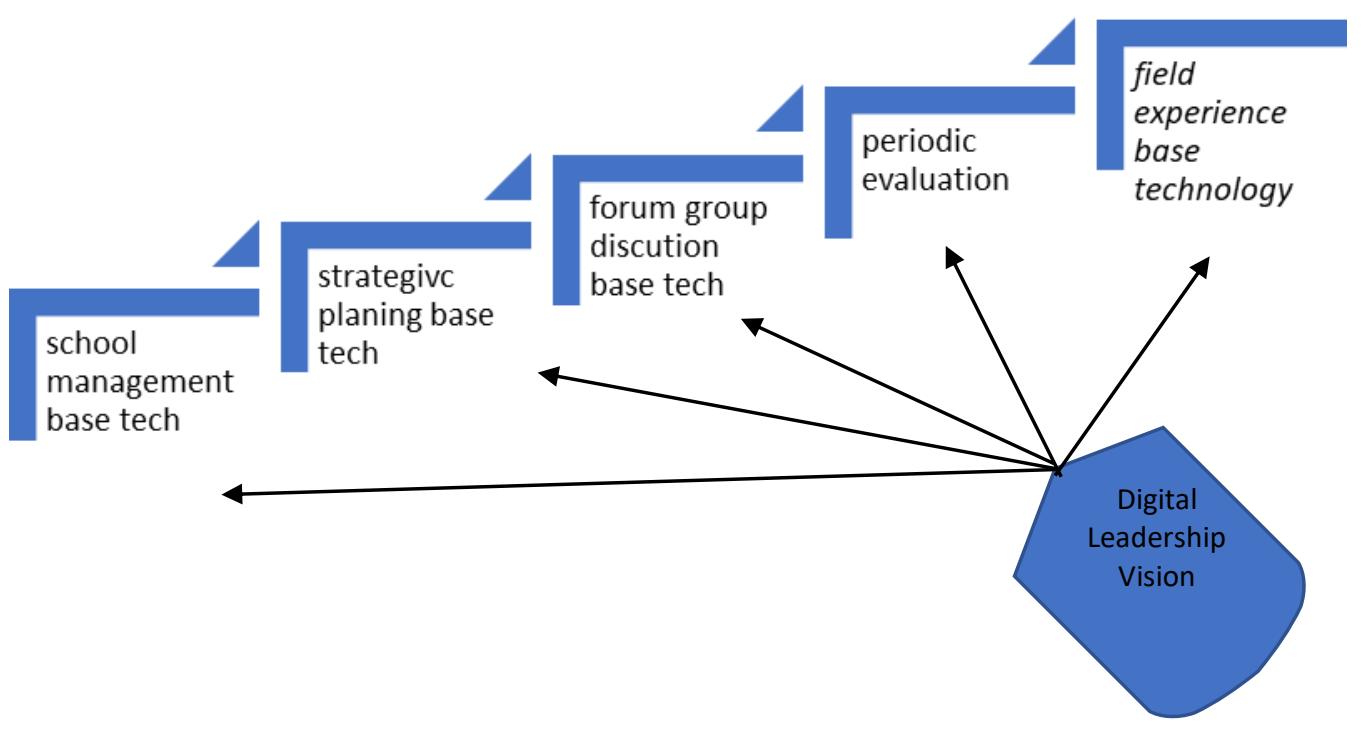

Gambar 1. Skema Visi Kepemimpinan Digital

\section{SIMPULAN}

Berdasarkan pada hasil dan pembahasan tentang visi kepemimpinan digital kepala sekolah dasar MIN 1 Kota Malang, maka dapat disimpulkan bahwa kepala sekolah dasar MIN 1 Kota Malang memiliki visi kepemimpinan digital teraktualisasikan dalam aktivitas kepemimpinan berikut ini:

Dalam pengelolaan sekolah dasar MIN 1 Kota Malang, kepala sekolah menerapkan model pengelolaan dengan manajemen berbasis teknologi. Manajemen berbasis teknologi ini diimplementasikan di dalam upaya kepala sekolah untuk merencanakan, mengorganisasi, mengimplementasikan dan mengendalikan seluruh aktifitas kepemimpinannya. Dengan manajemen sekolah berbasis teknologi ini, kepala sekolah dapat menggerakkan seluruh anggotanya secara efektif dan efisien.

Kepala sekolah menyusun perencanaan strategis sekolah dengan cara mengoptimalkan pemanfaatan teknologi sebagai proses penyusunan ataupun sebagai tujuan pengembangannya. Pemanfaatan secara proses terlihat pada saat kepala sekolah memanfaatakan teknologi untuk menyusunnya, sedangkan dalam konteks teknologi sebagai tujuan pengembangan terlihat di dalam isi dari rencana strategis itu sendiri. Rumusan konseptual perencanaan strategis tertuang dalam dokumen rencana strategi, rencana kerja, rencana kegiatan dan anggaran sekolah. Di dalam dokumen tersebut, tergambar bagaimana visi kepala sekolah yang 
menjadikan teknologi sebagai sesuatu yang sangat penting bagi pengembangan sekolah.

Kepala sekolah mengembangkan budaya diskusi dalam bentuk kelompokkelompok kecil di dalam sekolah yang di nahkodainya. Kelompok-kelompok kecil tersebut termediasi dalam grup-grup media komunikasi yang berbasis pada teknologi. Dari grup-grup inilah, kepala sekolah menggali dan mengelaborasi isuisu strategis bagi pengembangan sekolah dan muncul grup-grup diskusi guru dan karyawan untuk mengembangkan sekolah.

Adanya evaluasi secara peridoik dan berkelanjutan yang dilakukan oleh kepala sekolah dalam rangka mengontrol mutu dan kualitas lembaga. Evaluasi yang dilakukan oleh kepala sekolah tidak terlepas dari pemanfaatan teknologi didalam prosesnya, sehingga proses evaluasi yang dilakukan oleh kepala sekolah juga berbasiskan pada pemanfaatan teknologi.

Terakhir, kepala sekolah melakukan upaya pengembangan berbasiskan pada pengalaman otentik secara langsung di lapangan dengan dipandu dan di bawah bimbingan tenaga ahli. Dalam konteks ini, kepala sekolah menjadikan pengalamannya secara langsung di dalam mengembangkan sekolah dengan berbasiskan pada teknologi.

\section{DAFTAR RUJUKAN}

Alexandru, A. et al. (2019) 'Shaping the digital citizen into a smart citizen on the basis of iot capabilities', in Proceedings - 2019 22nd International Conference on Control Systems and Computer Science, CSCS 2019. doi: 10.1109/CSCS.2019.00126.

Anwaruddin, A. (2009) 'e-LEADERSHIP: Faktor Kunci Pengembangan Kapasitas Teknologi Informasi dan Komunikasi di Daerah', Puslitbang Sistem Informasi dan Otomasi Administrasi Negara. http://dx.doi.org/10.1016/j.automatica.2009.07.029.

Baxter, P., Susan Jack and Jack, S. (2008) 'Qualitative Case Study Methodology: Study Design and Implementation for Novice Researchers', The Qualitative Report Volume. doi: 10.2174/1874434600802010058.

Bogdan, R. and Biklen, S. K. (2003) 'Bogdan, R. C \& Biklen, S. K. (2003). Qualitative Research for Education: An introduction to Theories and Methods (4th ed.). New York: Pearson Education group. (pp. 110-120).', Qualitative Research for Education: An introduction to Theories and Methods.

Brett, J. (2019) Evolving Digital Leadership: How to Be a Digital Leader in 
Tomorrow's Disruptive World. Australia: Forest Lodge, New South Wales.

Creswell, J. W. (2012) Educational research: Planning, conducting, and evaluating quantitative and qualitative research, Educational Research. doi: 10.1017/CB09781107415324.004.

Crowe, S. et al. (2011) 'The case study approach', BMC Medical Research Methodology, 11. doi: 10.1186/1471-2288-11-100.

Flyvbjerg, B. (2006) 'Five misunderstandings about case-study research', Qualitative Inquiry. doi: 10.1177/1077800405284363.

Forrest-Lawrence, P. (2019) 'Case study research', in Handbook of Research Methods in Health Social Sciences. doi: 10.1007/978-981-10-5251-4_67.

Frey, C. B. and Berger, T. (2016) 'Leadership Skills for Digital and Key Enabling Technologies', (January), p. 156.

Fried, E. (2017) 'Digital Leadership - Company Leadership in the Age of Digital Transformation BWC White Paper 1 . Digital Leadership - Company Leadership in the Age of digital Transformation', (February), pp. 1-10.

Fullan, M. et al. (no date) 'Praise for Digital Leadership'.

Hamilton, J. R., Tee, S. and Prince, K. (2016) 'Corporate leadership in the digital age', in Proceedings of the International Conference on Electronic Business (ICEB).

Heikka, J. et al. (2019) 'Distributed pedagogical leadership and teacher leadership in early childhood education contexts', International Journal of Leadership in Education. $\quad$ Routledge, $00(00), \quad$ pp. 1-16. doi: 10.1080/13603124.2019.1623923.

Hox, J. J. and Boeije, H. R. (2004) 'Data Collection, Primary vs. Secondary', in Encyclopedia of Social Measurement. doi: 10.1016/B0-12-369398-5/00041-4.

International Society for Technology in Education (2009) 'National Educational Technology Standards for Administrators (NETS-A).', 5191.

ISTE (2001) 'ISTE Technology Leadership Standards', 5191, pp. 1-5.

Jamshed, S. (2014) 'Qualitative research method-interviewing and observation', Journal of Basic and Clinical Pharmacy, 5(4), p. 87. doi: 10.4103/09760105.141942.

Johnson, K. E. and Stake, R. E. (1996) 'The Art of Case Study Research', The Modern Language Journal. doi: 10.2307/329758. 
Kurland, H., Peretz, H. and Hertz-Lazarowitz, R. (2010) 'Leadership style and organizational learning: The mediate effect of school vision', Journal of Educational Administration, 48(1), pp. 7-30. doi: 10.1108/09578231011015395.

Lincoln, Y. S., Guba, E. G. and Pilotta, J. J. (1985) 'Naturalistic inquiry', International Journal of Intercultural Relations. doi: 10.1016/0147-1767(85)90062-8.

Malang, M. 1 K. (no date) PROFIL SEKOLAH. Available at: https://min1kotamalang.sch.id/profil/.

Matthew B, Miles, A. M. H. and Saldaña, J. (2014) Qualitative data analysis: a methods. Arizona State University.

Medicine, D. (2019) 'Digital clinical trials : creating a vision for the future', pp. 2-4. doi: 10.1038/s41746-019-0203-0.

Meyer, C. B. (2001) 'A Case in Case Study Methodology', Field Methods. doi: $10.1177 / 1525822 \times 0101300402$.

Mifsud, D. (2017) 'Distributed leadership in a Maltese college: the voices of those among whom leadership is "distributed" and who concurrently narrate themselves as leadership "distributors"', International Journal of Leadership in Education, 20(2), pp. 149-175. doi: 10.1080/13603124.2015.1018335.

Moos, L. (2003) 'Educational leadership: Leadership for/as Bildung?', International Journal of Leadership in Education, 6(1), pp. 19-33. doi: 10.1080/1360312022000038522.

Naderifar, M., Goli, H. and Ghaljaie, F. (2017) 'Snowball Sampling: A Purposeful Method of Sampling in Qualitative Research', Strides in Development of Medical Education. doi: 10.5812/sdme.67670.

Ndalamba, K. K., Caldwell, C. and Anderson, V. (2018) 'Leadership vision as a moral duty', Journal of Management Development, 37(3), pp. 309-319. doi: 10.1108/JMD-08-2017-0262.

Oberer, B. and Erkollar, A. (2018) 'Leadership 4.0: Digital Leaders in the Age of Industry 4.0', International Journal of Organizational Leadership, 7(4), pp. 404-412. doi: 10.33844/ijol.2018.60332.

Richardson, J. W. et al. (2012) 'NETS•A scholarship: A review of published literature', Journal of Research on Technology in Education, 45(2), pp. 131151. doi: 10.1080/15391523.2012.10782600.

Ruiz, V. et al. (2019) 'Implications of vertical policy integration for sustainable 
development implementation in higher education institutions', Journal of Cleaner Production. Elsevier Ltd, 235, pp. 733-740. doi: 10.1016/j.jclepro.2019.07.022.

Sheninger, E. (2014) 'Pillars of Digital Leadership', International Center for Leadership in Education, p. 4.

Sheninger, E. (2019) 'DIGITAL LEADERSHIP: CHANGING PARADIGMS FOR CHANGING TIMES', in INTED2019 Proceedings. doi: 10.21125/inted.2019.2528.

Yin, R. (2007) Fallstudier: design och genomförande, Liber. 